\title{
Er-Yb Waveguide Amplifiers in Novel Silicate Glasses
}

\author{
František Ondráček, Jana Jágerská, Linda Salavcová, Martin Míka, Jarmila Špirková, and \\ Jiř́ Čtyroký, Senior Member, IEEE
}

\begin{abstract}
A set of novel silicate glasses containing $\mathrm{ZnO}$ and co-doped with $\mathrm{Er}^{3+}$ and $\mathrm{Yb}^{3+}$ was designed as substrates for optical waveguide amplifiers. Characterized by exceptionally low up-conversion, minimum Er concentration quenching and high mechanical as well as chemical stability, the reported glasses can compete with phosphate-based materials typically used in the state-of-art active devices. Straight channel waveguides with propagation losses as low as $0.18 \mathrm{~dB} / \mathrm{cm}$ were fabricated in these substrates using $\mathrm{Ag}^{+} \Leftrightarrow \mathrm{Na}^{+}$and $\mathbf{K}^{+} \Leftrightarrow \mathrm{Na}^{+}$thermal ion exchange. Net on-chip gain values of $6.7 \mathrm{~dB}$ at $1537 \mathrm{~nm}$ were measured and a net fiber to-fiber gain of $5 \mathrm{~dB}$ was achieved when pumped at $976 \mathrm{~nm}$. A six-level spatially resolved numerical model of an Er-Yb co-doped active waveguide was developed to analyze and optimize the amplifier performance. Modification of the rare-earth dopant concentration and the channel waveguide geometry was proposed to increase the gain figure and improve the overall amplifier efficiency.
\end{abstract}

Index Terms-Channel waveguides, Er-Yb-doped glass, ion exchange, optical waveguide amplifier.

\section{INTRODUCTION}

$\mathbf{O}$ VER the past few decades, the huge expansion of telecommunication systems has led to development of many assorted optical components. In fiber optic communications, optical transmitters, fibers, fiber amplifiers and optical receivers are routinely used. Hand in hand with increasing speed of data transmission, the importance of integrated photonic devices and circuits grows. The use of dense wavelength-division multiplexing (DWDM) requires broad-band and code-transparent devices such as splitters, couplers, de/multiplexers, and waveguide amplifiers. In this concept, a lossless splitter for signal distribution into a number of outputs combined with an optical amplifier and a pump-signal de/multiplexer is highly desirable, especially in the local area networks. Many research groups have focused on the development of optical amplifiers

Manuscript received October 11, 2007; revised January 7, 2008. This work was supported by the Czech Science Foundation of the Czech Republic under Projects 106/08/0706 and 102/05/0987.

F. Ondráček and J. Čtyroký are with the Institute of Photonics and Electronics AS CR, 18251 Prague 8, Czech Republic (e-mail: ondracek@ufe.cz; ctyroky@ufe.cz).

J. Jágerská was with the Institute of Photonics and Electronics AS CR, 18251 Prague 8, Czech Republic. She is now with the Institute of Quantum Photonics and Electronics, Swiss Federal Institute of Technology, Lausanne (EPFL), CH-1015 Lausane, Switzerland (e-mail: jana.jagerska@epfl.ch).

L. Salavcová, M. Míka, and J. Špirková are with the Institute of Chemical Technology, Technická 5, 16628 Prague 6, Czech Republic (e-mail: salavcol@seznam.cz; martin.mika@vscht.cz; jarmila.spirkova@vscht.cz).

Color versions of one or more of the figures in this paper are available online at http://ieeexplore.ieee.org.

Digital Object Identifier 10.1109/JQE.2008.918302 operating at $1550 \mathrm{~nm}$, frequently based on erbium-doped materials. Erbium-doped glass-based waveguide amplifiers are appealing because of their potential to realize broad-band and inherently linear IO components compatible with current optical communication technology (see [1]-[3] and references therein).

Traditional techniques of the active waveguide fabrication include flame hydrolysis, chemical vapor deposition with subsequent reactive ion etching, or ion exchange [4]-[6]. The latter is an effective and cheap fabrication technique [7], which has already allowed development of low-loss straight as well as bent channel waveguides. Concerning the devices, $1 \times 32$ coupler [8] is being commercially used, and the integrated pump-signal $(980 \mathrm{~nm} / 1550 \mathrm{~nm})$ de/multiplexer [9] has been recently developed. The only major disadvantage of the ion exchange technique is that it requires thoughtful adjustment of the technological procedure appropriate for a certain combination of a chosen glass substrate [6] and the expected utilization of the waveguide. However, once the fabrication procedure is adjusted, this technique enables formation of huge amount of low-cost waveguides with fully reproducible properties.

Erbium-doped waveguides and lasers have been mainly developed in multicomponent silicate and phosphate glasses. Especially phosphate glasses are famous for enabling high concentration of rare-earth dopants to be dissolved in the glass matrix, which results in fabrication of active devices of small-size and high gain up to $4.1 \mathrm{~dB} / \mathrm{cm}$ [10]. On the contrary, silicate glasses have the advantage of higher mechanical rigidity and chemical stability, lower cost and better compatibility with current commercial optical fibers (refractive index and subsequent coupling efficiency, material dispersion, etc.).

As for silicate glasses, $\mathrm{Al}_{2} \mathrm{O}_{3}$ is typically used to enhance the solubility and homogeneity of rare earth dopants and to reduce the rate of Er-pairs and clusters formation [1]. Nevertheless, we have shown recently [11] that the presence of $\mathrm{ZnO}$ in the glass can also contribute to a substantial enhancement of rare earth solubility. In this paper we report on optical gain measurements on waveguides in Er-doped and $\mathrm{Er}-\mathrm{Yb}$ co-doped $\mathrm{ZnO}-\mathrm{SiO}_{2}$-based glasses. Preliminary results presented at ECIO 2007 conference [12] have been thoroughly revised and completed, and new results of numerical optimization of waveguide amplifiers showing great potential of new substrate glasses have been included.

\section{FABRICATION}

Three different types of Er-doped and Er-Yb-co-doped silicate glasses containing $\mathrm{ZnO}$ were prepared by standard melting technique from the following oxide constituents: $\mathrm{SiO}_{2}, \mathrm{Na}_{2} \mathrm{O}$ 
TABLE I

CONCENTRATION OF THE RARE-EARTH IONS $\left[\mathrm{at} / \mathrm{m}^{3}\right.$ ]

\begin{tabular}{|l|c|c|c|}
\hline Glass label & MM64 & MM65 & MM66 \\
\hline $\mathrm{Er}_{2} \mathrm{O}_{3}$ & $1.71 \times 10^{26}$ & $1.71 \times 10^{26}$ & $1.71 \times 10^{26}$ \\
\hline $\mathrm{Yb}_{2} \mathrm{O}_{3}$ & - & $1.70 \times 10^{26}$ & $3.40 \times 10^{26}$ \\
\hline
\end{tabular}

(14.2 mol\%), $\mathrm{ZnO}, \mathrm{Al}_{2} \mathrm{O}_{3}, \mathrm{Er}_{2} \mathrm{O}_{3}$ and $\mathrm{Yb}_{2} \mathrm{O}_{3}$. The samples, referred as MM64, MM65 and MM66, contain the same fraction of $\mathrm{Er}^{3+}$ dopants (0.6 at.\%) and differ in the $\mathrm{Yb}^{3+}$ concentration, which is zero in purely Er-doped MM64 and increases to 0.6 and 1.2 at.\% for MM65 and MM66, respectively, as summarized in Table I.

The exact glass composition followed from a detailed optimization study [11] with the aim to increase the solubility and homogeneity of $\mathrm{Er}^{3+}$ and $\mathrm{Yb}^{3+}$ ions using the network intermediate $\mathrm{ZnO}$. $\mathrm{ZnO}$ decreases the optical basicity of the glass, which was proven to have a positive influence on the metastable level lifetime, luminescence bandwidth and absorption and emission cross section spectra of the $\mathrm{Er}^{3+}$ ions [11].

All glass components were melted together for $4.5 \mathrm{~h}$ in a platinum crucible at the temperature of $1470{ }^{\circ} \mathrm{C}$. Removal of most of air bubbles and better homogenization was done by mechanical stirring in the first $75 \mathrm{~min}$ of the melting process. Afterwards, the melt was quenched in a water bath and then left to temper in the oven at $520{ }^{\circ} \mathrm{C}$ for another hour to reduce the residual stress. The glass bulk was finally cut into wafers and polished to dimensions of $40 \times 20 \times 2 \mathrm{~mm}^{3}$ for waveguide fabrication.

In order to define the channel waveguide boundaries, standard optical contact lift-off lithography was used. The actual waveguide pattern consisted of a series of straight waveguide channels varying in width from 2 to $6.5 \mu \mathrm{m}$. The major advantage of this pattern design was that regardless of small inaccuracy in the ion exchange condition settings, one could find a channel that exhibited a single-mode performance at both pump $(976 \mathrm{~nm})$ and signal $(1537 \mathrm{~nm})$ wavelengths.

In the glass substrates, waveguides were formed using the $\mathrm{K}^{+} \Leftrightarrow \mathrm{Na}^{+}$and $\mathrm{Ag}^{+} \Leftrightarrow \mathrm{Na}^{+}$thermal ion exchange technique. This was feasible thanks to a large fraction of network modifier $\mathrm{Na}_{2} \mathrm{O}$ contained in the glass matrix. Potassium and silver ion-exchanged waveguides differ actually a lot in both their fabrication conditions and waveguiding properties. The process of ion exchange with $\mathrm{K}^{+}$ions was performed in a melt of pure potassium nitrate at $400{ }^{\circ} \mathrm{C}$ for various times, depending on the exact $\mathrm{Yb}$ concentration in the glass substrate. The $\mathrm{Ag}^{+}$ion exchange proceeded in eutectic $\mathrm{NaNO}_{3}-\mathrm{KNO}_{3}$ melt with addition of $3.6 \mathrm{wt} . \%$ of silver nitrate at $280^{\circ} \mathrm{C}$, as shown in Table II. While potassium channel waveguides exhibit lower propagation losses, the resulting refractive index contrast is low as well leading to large mode field area. Silver waveguides, on the contrary, can account for higher mode confinement; however, the inherent propagation loss is increased.

\section{SPeCtroscopic AND WAVEguide Properties}

The relative absorption and emission cross section spectra at both pump and signal wavelengths were obtained from the
TABLE II

CONDITIONS OF THE THERMAL ION EXCHANGE

\begin{tabular}{|l|c|c|c|}
\hline Glass label & MM64 & MM65 & MM66 \\
\hline $\mathrm{K}^{+} \Leftrightarrow \mathrm{Na}^{+}$ & $1.5 \mathrm{~h} / 400^{\circ} \mathrm{C}$ & $2.3 \mathrm{~h} / 400^{\circ} \mathrm{C}$ & $3.2 \mathrm{~h} / 400^{\circ} \mathrm{C}$ \\
\hline $\mathrm{Ag}^{+} \Leftrightarrow \mathrm{Na}^{+}$ & - & $6 \mathrm{~min} / 280^{\circ} \mathrm{C}$ & $8 \mathrm{~min} / 280^{\circ} \mathrm{C}$ \\
\hline
\end{tabular}

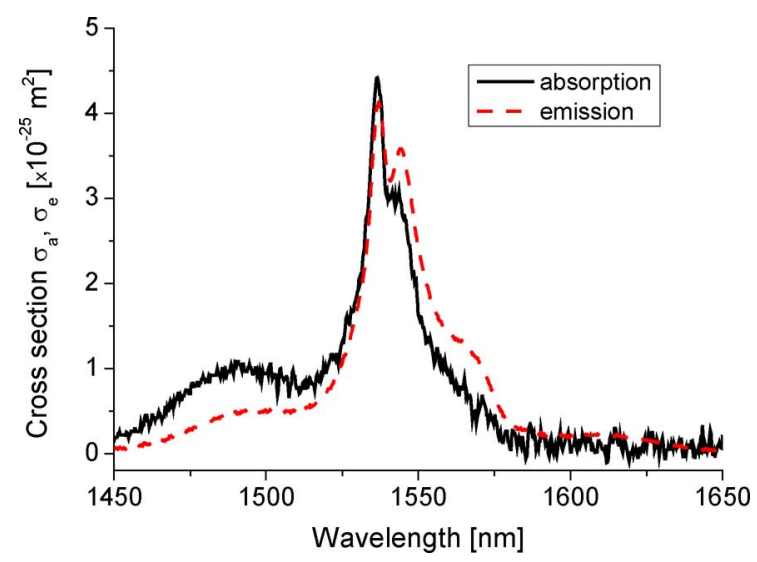

Fig. 1. Spectral dependency of the cross section of MM65 glass substrate.

bulk transmission and photoluminescence measurements. An example for the MM65 glass is presented in Fig. 1.

The relative absorption cross section spectrum was normalized by means of the measured waveguide transmission at the signal peak absorption wavelength. Knowing the optical mode profile, waveguide transmission and the $\mathrm{Er}^{3+}$ concentration, the peak absorption cross section at $1537 \mathrm{~nm}$ was found to be $4.42 \times 10^{-25} \mathrm{~m}^{2}$. Absorption cross section of $\mathrm{Er}^{3+}$ at the pump wavelength of $976 \mathrm{~nm}$ resulted in $1.25 \times 10^{-25} \mathrm{~m}^{2}$, while the absorption cross section of ytterbium amounted to $8.4 \times 10^{-25} \mathrm{~m}^{2}$ in both MM65 and MM66 samples.

Normalization constant for the emission cross section spectra was calculated using the McCumber procedure [14]. The peak emission cross section of $\mathrm{Er}^{3+}$ at $1537 \mathrm{~nm}$ has the value of $4.22 \times 10^{-25} \mathrm{~m}^{2}$ and the cross section of ytterbium at $976 \mathrm{~nm}$ equals $6.7 \times 10^{25} \mathrm{~m}^{2}$.

Finally, the metastable level lifetime of $\mathrm{Er}^{3+}$ ion was obtained from the photoluminescence decay measurement. The detected decay curve was first order exponential with the time constant of $9.43 \mathrm{~ms}$ in MM64 and $9.40 \mathrm{~ms}$ in Yb-doped MM65 and MM66 samples. Within the probed rare-earth concentration limit, the $\mathrm{Er}^{3+}$ radiative lifetime did not substantially depend on the of the $\mathrm{Yb}^{3+}$ concentration.

As regards the waveguide properties, intensity profiles of the guided modes as well as waveguide scattering losses were experimentally determined. The mode field profiles at the signal and pump wavelengths were obtained by near-field IR imaging of the waveguide output facets. In potassium waveguides, the mode dimensions at $1 / \mathrm{e}^{2}$ of the peak intensity were found to be $8 \times 12 \mu \mathrm{m}^{2}$ at $980 \mathrm{~nm}$ and $11 \times 14 \mu \mathrm{m}^{2}$ at $1550 \mathrm{~nm}$. The silver ion-exchange waveguides had the mode dimensions of $7 \times 8 \mu \mathrm{m}^{2}$ and $3.5 \times 5 \mu \mathrm{m}^{2}$ at the pump and probe wavelengths, respectively. Although the large mode field area in the $\mathrm{K}^{+}$channel waveguides can ensure low coupling loss to 


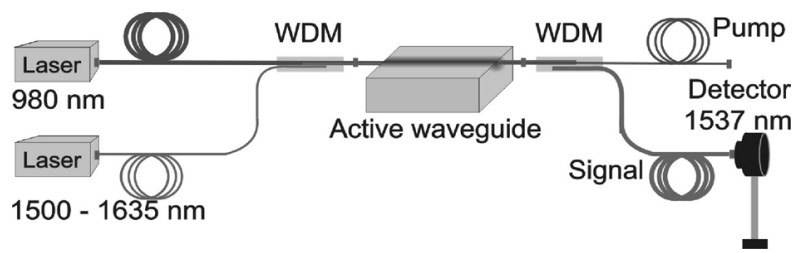

Fig. 2. Experimental setup for amplification measurement.

standard single-mode fibers, it naturally results in undesirably low pump efficiency. Both higher confinement of intensity distribution and better overlap of pump and signal intensity profiles could be achieved if more sophisticated waveguide fabrication techniques were utilized (e.g., two-step field-assisted ion-exchange, burying the waveguide below the glass surface [8]).

The channel waveguide scattering loss was determined outside the Er absorption bands at $1600 \mathrm{~nm}$ using the Fabry-Perot resonator method [13]. Potassium channel waveguides exhibited losses as low as $0.18 \mathrm{~dB} / \mathrm{cm}$, while the losses of silver exchanged channel waveguides were in the range of $0.8-0.9 \mathrm{~dB} / \mathrm{cm}$. In the latter case, the losses could be reduced by half after annealing for $30 \mathrm{~min}$ at $300^{\circ} \mathrm{C}$, however, at the expense of considerable mode field expansion.

\section{Gain Measurement}

Optical gain measurements were performed on 38-mm-long waveguide samples using the experimental setup depicted in Fig. 2. A semiconductor laser diode of maximum optical power $375 \mathrm{~mW}$ emitting at $976 \mathrm{~nm}$ served as a pump source, and the signal was supplied by a highly monochromatic Agilent $81642 \mathrm{~B}$ laser tunable in the wavelength range of $1495-1635 \mathrm{~nm}$.

The signal and pump radiation were combined by a 980/1550-nm fiber WDM and coupled into the channel waveguides using a SM $980(4.5 / 125-\mu \mathrm{m})$ fiber exhibiting single-mode performance at both signal and pump wavelengths. At the waveguide output the amplified signal was separated from the pump radiation in the second 980/1550-nm fiber WDM coupler and detected using an InGaAs detector. At the waveguide input and output a coupling gel was used to suppress Fresnel reflections and thus to minimize the coupling losses. In potassium channel waveguides the resulting loss per interface was estimated to 0.8 and $0.85 \mathrm{~dB}$ at the signal and pump wavelengths, respectively. For silver waveguides with higher refractive index contrast and stronger mode field confinement, the coupling loss was considerably higher, approximately $1.8 \mathrm{~dB}$.

First, the change in signal transmission as a function of pump power was measured at the central $\mathrm{Er}^{3+}$ ion emission wavelength of $1537 \mathrm{~nm}$. The signal power was set to $100 \mu \mathrm{W}$. The measured signal enhancement was converted to the net optical gain by setting the gain at $1600 \mathrm{~nm}$, where the $\mathrm{Er}^{3+}$ absorption is negligible, equal to the waveguide scattering loss.

Fig. 3 shows the results of gain measurement on potassium channel waveguides fabricated in MM64 and MM65 glass substrates. In the purely Er-doped sample the positive net optical gain is achieved at the pump power of $130 \mathrm{~mW}$ and upon pumping at $316 \mathrm{~mW}$ reaches up to $4.0 \mathrm{~dB}$.

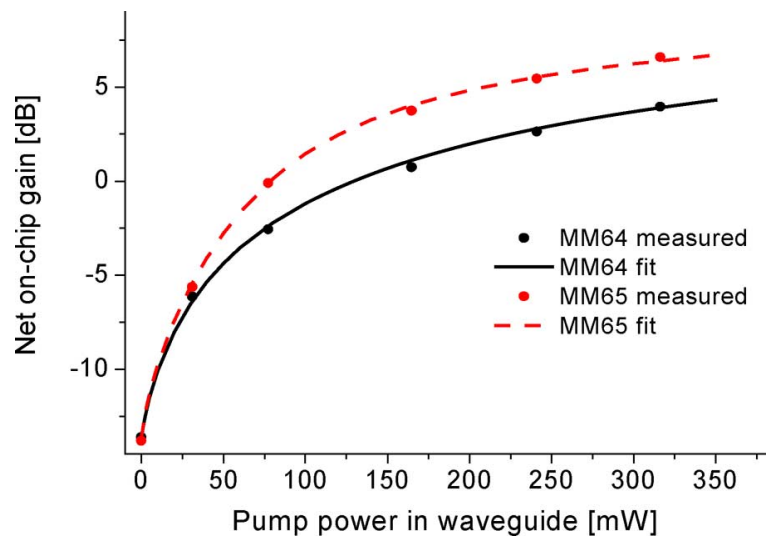

Fig. 3. Net on-chip gain versus pump power: measured and simulated data for $\mathrm{K}^{+}$channel waveguides in MM64 (Er only) and MM65 (Er : $\mathrm{Yb} \sim 1: 1$ ) glasses.

TABLE III

MAXIMUM ACHIEVED NET ON-CHIP GAIN

\begin{tabular}{|l|c|c|}
\hline \multirow{2}{*}{} & \multicolumn{2}{|c|}{ Net on-chip gain [dB per sample] } \\
\cline { 2 - 3 } & $\mathrm{K}^{+}$waveguide & $\mathrm{Ag}^{+}$waveguide / after annealing \\
\hline MM64 & 3.95 & $-/-$ \\
\hline MM65 & 6.61 & $5.80 / 5.50$ \\
\hline MM66 & $6.63^{*}$ & $6.31 / 6.71$ \\
\hline
\end{tabular}

* the length of the sample was only $34 \mathrm{~mm}$

The performance of the Er-Yb-co-doped sample is even better with the threshold pump power reduced to $80 \mathrm{~mW}$ and with the maximum achievable gain of $6.6 \mathrm{~dB}$. Thanks to sufficiently low input/output coupling losses of potassium waveguides, fiber to-fiber gain as high as $4.9 \mathrm{~dB}$ was observed.

The optical gain measurements on silver channel waveguides were performed on MM65 and MM66 glass substrates. Despite stronger mode field confinement as compared to potassium waveguides, the maximum net gain amounted for only 5.8 and $6.3 \mathrm{~dB}$ in MM65 and MM66, respectively. This was due to approximately five times larger scattering loss of $\mathrm{Ag}^{+}$channel waveguides. Furthermore, because of substantial coupling loss, fiber to-fiber gain of only $2.6 \mathrm{~dB}$ was observed.

The annealing process had a positive influence on both the scattering and coupling loss, however, the pump and signal field confinement was reduced. After annealing for $30 \mathrm{~min}$ at $300{ }^{\circ} \mathrm{C}$ the maximum net gain measured in MM65 and MM66 glasses was 5.5 and $6.7 \mathrm{~dB}$, respectively. The fiber to-fiber gain increased to $4.1 \mathrm{~dB}$. All measurement results are summarized in Table III.

Further, we focused on determining the amplifier bandwidth by measuring the spectral dependence of signal gain at several pump power levels.

The input signal level was kept constant at $P_{s}=100 \mu \mathrm{W}$ and the measurement was performed in the full achievable wavelength range from 1495 to $1635 \mathrm{~nm}$. The gain spectrum of $\mathrm{K}^{+}$ sample in MM66 glass is depicted in Fig. 4 and is characterized by a relatively narrow full-width at half-maximum (FWHM) bandwidth of $15 \mathrm{~nm}$, which is quite typical for ordinary silicate glass [1].

Finally, spectral analysis of the amplified signal was performed and it showed that essentially no amplified spontaneous 


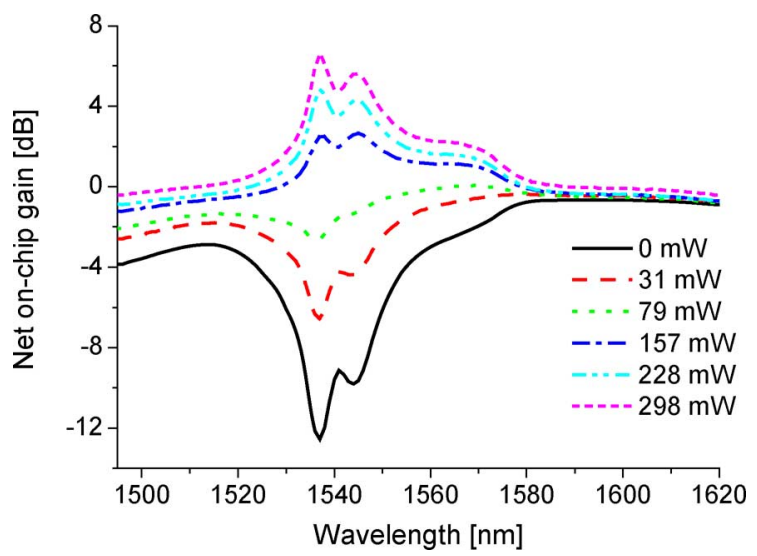

Fig. 4. Measured spectral dependency of the net on-chip gain of the $\mathrm{K}^{+}$ channel waveguide in MM66 (Er : Yb $=1: 2)$ glass for several different pump powers (converted to input power in the waveguide).

emission, degrading the amplifier performance and contributing to noise figure, was present.

\section{Model Simulation And Discussion}

A six-level numerical model of Er-Yb-co-doped active waveguide was formulated to fit the measured gain and to analyze the amplifier performance. The model incorporates the $\mathrm{Er}-\mathrm{Yb}$ rate and propagation equations on a 3-D grid to calculate the population inversion and the pump and signal evolution along the waveguide. It takes into account the cooperative signal up-conversion as the most important quenching effect limiting the amplifier gain. Next, the Er-Yb cross-relaxation process as a mechanism of energy transfer between $\mathrm{Er}^{3+}$ and $\mathrm{Yb}^{3+}$ ions is considered [15].

All input data (Table IV) for the model calculations were taken from the experimental results reported above except for the nonradiative lifetimes and the $\mathrm{Yb}^{3+}$ metastable level lifetime, which were taken from [1] and [16]. The up-conversion coefficient $C_{\text {up }}$ and the cross relaxation coefficient $C_{\text {cr }}$ as defined in [15] represented the unknown parameters to be found upon the fitting procedure.

First, the up-conversion coefficient $C_{\mathrm{up}}$, which governs the rate at which the $\mathrm{Er}^{3+}$ ions are promoted to the inactive $4 I^{9 / 2}$ level, was determined from the measurement on purely Er-doped MM64 glass. The best fit of the measured data was found for the value $C_{\mathrm{up}}=1.1 \pm 0.2 \times 10^{-24} \mathrm{~m}^{3} \mathrm{~s}^{-1}$. Here the inaccuracy reflects a $5 \%$ possible error in the measured mode field dimensions and uncertainty of $0.1 \mathrm{~dB}$ in the experimentally determined scattering loss of the channel waveguide.

This is one of the lowest $C_{\text {up }}$ values reported for a glass material with $\mathrm{Er}^{3+}$ concentration as high as 0.6 at.\%. Low probability of the up-conversion can be also qualitatively deduced from the fact that no visible green luminescence indicating the pump up-conversion was observed during the measurement.

The cross-relaxation coefficient was obtained by fitting the data measured on MM65 and MM66 glasses. The best fit shown in Fig. 3 was achieved for $C_{\text {cr }}=0.12^{-22} \mathrm{~m}^{3} \mathrm{~s}^{-1}$. The $\mathrm{Yb}^{3+}$ $\mathrm{Er}^{3+}$ energy transfer efficiency can be estimated from the approximate equation for the cross-relaxation quantum efficiency [17]
TABLE IV

MODEL INPUT DATA

\begin{tabular}{|c|c|c|}
\hline \multicolumn{3}{|l|}{ Spectroscopic parameters } \\
\hline $\mathrm{Er}^{3+}$ abs. cross section@ $1537 \mathrm{~nm}$ & \multicolumn{2}{|c|}{$\sigma_{12}=4.42 \mathrm{e}^{-25} \mathrm{~m}^{2}$} \\
\hline $\mathrm{Er}^{3+}$ emis. cross section@1537 nm & \multicolumn{2}{|c|}{$\sigma_{21}=4.22 \mathrm{e}^{-25} \mathrm{~m}^{2}$} \\
\hline $\mathrm{Er}^{3+}$ abs. cross section @ $976 \mathrm{~nm}$ & \multicolumn{2}{|c|}{$\sigma_{13}=1.25 \mathrm{e}^{-25} \mathrm{~m}^{2}$} \\
\hline $\mathrm{Yb}^{3+}$ abs. cross section @ $976 \mathrm{~nm}$ & \multicolumn{2}{|c|}{$\sigma_{56}=8.40 \mathrm{e}^{-25} \mathrm{~m}^{2}$} \\
\hline $\mathrm{Yb}^{3+}$ emis. cross section@976 nm & \multicolumn{2}{|c|}{$\sigma_{65}=6.70 \mathrm{e}^{-25} \mathrm{~m}^{2}$} \\
\hline $\mathrm{Er}^{3+}$ metastable level lifetime & \multicolumn{2}{|c|}{$\tau_{21}^{\mathrm{Er}}=9.43 \mathrm{~ms}$} \\
\hline $\mathrm{Yb}^{3+}$ metastable level lifetime & \multicolumn{2}{|c|}{$\tau_{65}{ }^{\mathrm{Yb}}=1.3 \mathrm{~ms}$} \\
\hline $\mathrm{Er}^{3+}$-nonrad. lifetime of pump level & \multicolumn{2}{|c|}{$\tau_{32}{ }^{\mathrm{Er}}=10 \mu \mathrm{s}$} \\
\hline Up-Conversion coefficient & \multicolumn{2}{|c|}{$\mathrm{C}_{\mathrm{up}}=1.1 \mathrm{e}^{-24} \mathrm{~m}^{3} \mathrm{~s}^{-1}$} \\
\hline Cross-relaxation coefficient & \multicolumn{2}{|c|}{$\mathrm{C}_{\mathrm{cr}}=0.12 \mathrm{e}^{-22} \mathrm{~m}^{3} \mathrm{~s}^{-1}$} \\
\hline Waveguide parameters & $\mathrm{K}^{+}$ & $\mathrm{Ag}^{+}$ \\
\hline Mode-field dimensions@1550nm & $10.6 \times 14.2 \mu \mathrm{m}^{2}$ & $6.7 \times 7.7 \mu \mathrm{m}^{2}$ \\
\hline Mode-field dimensions@980nm & $7.6 \times 11.6 \mu \mathrm{m}^{2}$ & $3.5 \times 5.2 \mu \mathrm{m}^{2}$ \\
\hline Scattering loss@1550nm & $0.18 \mathrm{~dB} / \mathrm{cm}$ & $0.85 \mathrm{~dB} / \mathrm{cm}$ \\
\hline
\end{tabular}

TABLE V

Metastable LeVel Lifetime of ER:Yb Doped SAMPLes.

\begin{tabular}{|c|c|c|c|c|c|}
\hline & \multicolumn{5}{|c|}{ Lifetime (ms) } \\
\hline Yb (at.\%) & 0.5 & 1 & 1.5 & 2 & 2.5 \\
\hline 1 & 9.49 & 7.30 & 5.46 & 4.40 & 3.69 \\
\hline 2 & 7.67 & 6.92 & 5.38 & 4.27 & 3.52 \\
\hline 3 & 8.82 & 6.60 & 5.42 & 4.14 & 3.51 \\
\hline
\end{tabular}

*data were measured at IFAC-CNR in Firenze, Italy (Section of optoelectronics and photonics headed by prof. G.C. Righini)

$$
\eta=\frac{C_{\mathrm{cr}} N_{\mathrm{Er}} \tau_{65}^{\mathrm{Yb}}}{1+C_{\mathrm{cr}} N_{\mathrm{Er}} \tau_{65}^{\mathrm{Yb}}\left(1+\frac{N_{\mathrm{Yb}^{2}} \tau_{32}^{\mathrm{Er}}}{N_{\mathrm{Er}} \tau_{65}^{\mathrm{Yb}}}\right)}=72 \% .
$$

When fitting the cross-relaxation process we considered that the $C_{\mathrm{up}}$ coefficient keeps the constant value of $C_{\text {up }}=1 \cdot 10^{-24} \mathrm{~m}^{3} \mathrm{~s}^{-1}$.

This is equivalent to the assumption that the addition of $\mathrm{Yb}^{3+}$ into the glass matrix does not influence the solubility and the radiative properties of $\mathrm{Er}^{3+}$ (i.e., the $\mathrm{Yb}$-co-doping does not change the up-conversion probability). Since neither the reduction of the metastable level lifetime of $\mathrm{Er}^{3+}$ [see Table V], nor the degradation of an amplifier gain was observed with the increase in $\mathrm{Yb}$ concentration, this assumption appears to be reasonable.

It should be noted that the 38 -mm length of the active waveguides is not optimum. In purely Er-doped MM64 substrate, only a small portion of pump power was absorbed (pump power decrease of only $2 \mathrm{~dB}$ was measured), which means that higher gain could be achieved in longer samples. The simulation results imply that the gain of $6.3 \mathrm{~dB}$ would be feasible in a 10-cm-long Er-doped waveguide. On the other hand, in MM66 samples, the 


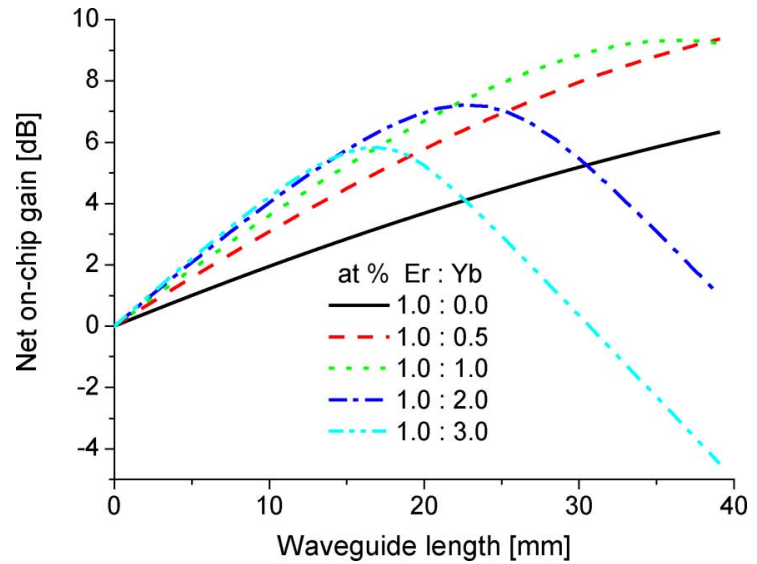

Fig. 5. Model simulation of the dependency of the net on-chip gain versus waveguide length and different Er: $\mathrm{Yb}$ concentration in $\mathrm{K}^{+}$waveguide.

end section of the waveguide is slightly "underpumped" due to strong absorption of pump power by $\mathrm{Yb}^{3+}$ ions.

Finally, the optimization of the glass composition with respect to the $\mathrm{Er}^{3+}$ and $\mathrm{Yb}^{3+}$ ion concentration was numerically simulated. The optimal concentration depends on both the length of the waveguide and the signal/pump mode field confinement.

For 40-mm-long sample fabricated by $\mathrm{K}^{+}$ion exchange with the same channel waveguide geometry as in our experiments (see Fig. 5), the optimum Er-Yb concentration was found 1 at.\% for both $\mathrm{Er}$ and $\mathrm{Yb}$. According to the simulation, such glass exhibits the net optical gain of $9 \mathrm{~dB}$. In shorter but otherwise identical samples, higher $\mathrm{Yb}^{3+}$ concentration is desired to compensate for rather low absorption cross section of $\mathrm{Er}^{3+}$.

For higher index-contrast waveguides with strongly confined guided field (e.g., signal $4 \times 4 \mu \mathrm{m}^{2}$, pump $3 \times 3 \mu \mathrm{m}^{2}$ ), the $\mathrm{Er}^{3+}$ concentration of 2.5 at.\% is optimum and no further addition of $\mathrm{Yb}^{3+}$ is required. In this case, much higher net on-chip gain up to $17 \mathrm{~dB}(6 \mathrm{~dB} / \mathrm{cm})$ upon $100-\mathrm{mW}$ pumping is predicted by the model calculations.

\section{CONCLUSION}

Channel optical waveguides in novel Er-doped and $\mathrm{Er}-\mathrm{Yb}$-co-doped $\mathrm{ZnO}$-containing silicate glasses were fabricated by a standard ion-exchange technique. Net-on-chip gain of $6.3 \mathrm{~dB}$ and $6.6 \mathrm{~dB}$ (measured at the wavelength of $1537 \mathrm{~nm}$ ) was achieved in 34-mm and 38-mm-long $\mathrm{Ag}^{+} \Leftrightarrow \mathrm{Na}^{+}$and $\mathrm{K}^{+} \Leftrightarrow \mathrm{Na}^{+}$ion-exchanged waveguides, respectively, when excited by a pump power of about $316 \mathrm{~mW}$ at the wavelength of $976 \mathrm{~nm}$. The active waveguide samples exhibited exceptionally low up-conversion $C_{\mathrm{up}}=1.1 \pm 0.2 \times 10^{-24} \mathrm{~m}^{3} \mathrm{~s}^{-1}$ and essentially no evidence for Er concentration quenching at the Er-concentration of 0.6 at.\%. The low up-conversion is due to the addition of $\mathrm{ZnO}$ intermediate into the glass matrix, however, the physically chemical mechanism behind is not completely clear and requires further investigation.

A numerical model was developed to analyze and optimize the amplifier performance. Optimum concentration of rare-earth ions in the substrate glass was found to be $\mathrm{N}_{r}=\mathrm{N}_{\mathrm{Yb}}=1$ at. $\%$ for the potassium channel waveguide. Very large net optical gain (up to $17 \mathrm{~dB} /$ sample) was simulated for an ideal overlap of the pump and signal optical field in a glass containing 2.5 at.\% of $\mathrm{Er}$ and no Yb. These results clearly demonstrate great potential of the reported silicate glass as a substrate material for advanced active waveguide devices.

\section{REFERENCES}

[1] W. J. Miniscalco, “Erbium-doped glasses for fiber amplifiers at 1500 nm," J. Lightw. Technol., vol. 9, no. 2, pp. 234-250, Feb. 1991.

[2] A. J. Kenyon, "Recent developments in rare-earth doped materials for optoelectronics," Progr. Quantum Electronics, vol. 26, pp. 225-284, 2002.

[3] L. Eldada, "Advances in telecom and datacom optical components," Opt. Eng., vol. 40, no. 7, pp. 1165-1178, 2001.

[4] G. C. Righini, S. Pelli, and M. Ferrari, "Er-doped silica-based waveguides prepared by different techniques: RF-sputtering, sol-gel and ionexchange," Opt. Quantum Electron., vol. 34, pp. 1151-1166, 2002.

[5] W. Huang, R. R. A. Syms, and E. M. Yeatman, "Fiber device-fiber gain from a sol-gel erbium-doped waveguide amplifier," IEEE Photonics Technology Letters, vol. 14, no. 7, pp. 959-961, Jul. 2002.

[6] F. Ondracek et al., "Fabrication and characterization of channel optical waveguides in Er-Yb-doped silicate glasses," in Opt. Mater., 2007, doi:10.1016/j.optmat.2006.12.004.

[7] S. I. Najafi, Introduction to Glass Integrated Optics. Boston, MA: Artech House, 1992.

[8] Planar Waveguide Products. Nova Paka, Czech Republic, SQS Vlaknova optika, a.s..

[9] D. Bucci, J. Grelin, E. Ghibaudo, and J.-E. Broquin, "Realization of a 980-nm/1550-nm pump-signal (de)multiplexer made by ion exchange on glass using a segmented asymetric Y-junction," IEEE Photon. Technol. Lett., vol. 19, no. 9, pp. 698-700, May 2007.

[10] Y. C. Yan, A. J. Faber, H. de Waal, Kik, and P. G. Polman, "Erbiumdoped phosphate glass waveguide on silicon with $4.1 \mathrm{~dB} / \mathrm{cm}$ gain at 1535 nm,” Appl. Phys. Lett., vol. 71, pp. 2922-2294, 1997.

[11] M. Míka, O. Kolek, J. Špirková, P. Capek, S. Berneschi, M. Brenci, G. N. Conti, S. Pelli, S. Sebastiani, and G. C. Righini, "The effect of $\mathrm{Ca}^{2+}, \mathrm{Mg}^{2+}$ and $\mathrm{Zn}^{2+}$ on optical properties of $\mathrm{Er}^{3+}$ doped silicate glass," Proc. SPIE, vol. 5723, pp. 63-70, 2005.

[12] J. Jágerská, F. Ondráček, L. Salavcová, M. Míka, J. Špirková, and J. Čtyroký, "Er-Yb waveguide amplifiers in novel silicate glasses," presented at the 13th Eur. Conf. Integrated Optics ECIO 2007, Copenhagen, Apr. 25-27, 2007, Paper ThG14.

[13] F. Ondráček, M. Skalský, and J. Čtyroký, "Characterization of optical waveguides with very different refractive-index contrast," Proc. SPIE, vol. 6180, pp. 6180414-6180146, 2006.

[14] W. J. Miniscalco and R. S. Quimby, "General procedure for the analysis of $\mathrm{Er}^{3+}$ cross sections," Opt. Lett., vol. 16, pp. 258-260, 1991.

[15] J. Jágerská, "Optical Waveguide Amplifiers in Er-Doped Glass Substrates," M.Sc. thesis, Czech Technical University, Prague, Czech Rep., 2006.

[16] M. P. Hehlen, N. J. Cockroft, and T. R. Gosnell, "Spectroscopic properties of $\mathrm{Er}^{3+}$ - and $\mathrm{Yb}^{3+}$-doped soda-lime silicate and aluminosilicate glasses," Phys. Rev. B, vol. 56, pp. 9302-9315, 1997.

[17] D. L. Veasey, D. S. Funk, P. M. Peters, N. A. Sanford, G. E. Obarski, N. Fontaine, M. Young, A. P. Peskin, W.-C. Liu, S. N. Houde-Walter, and J. S. Hayden, J. Non-Cryst. Solids, vol. 263, pp. 369-381, 2000.

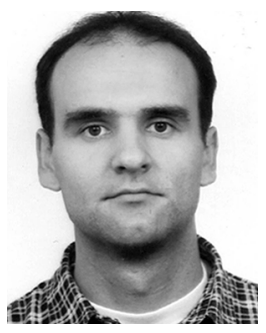

František Ondráček received the M.Sc. degree in electronics from the Czech Technical University, Prague, Czech Republic, in 2002. He is currently working towards the Ph.D. degree at the Institute of Photonics and Electronics ASCR, v.v.i., Prague, Czech Republic.

His current work includes fabrication and characterization of passive and active integrated photonic devices. 


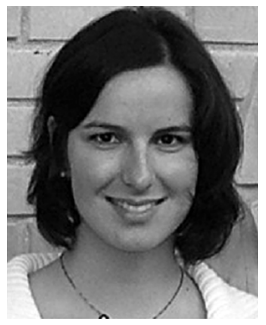

Jana Jágerská received the M.Sc. degree in physical electronics from the Czech Technical University, Prague, Czech Republic, in 2006 Her MSc. thesis was devoted to theoretical and experimental investigation of glass-based active photonic waveguides. Currently she is working towards the Ph.D. degree at the Swiss Federal Institute of Technology, Lausanne, Switzerland, in the field of 2-D photonic crystal devices and advanced nanophotonic structures.

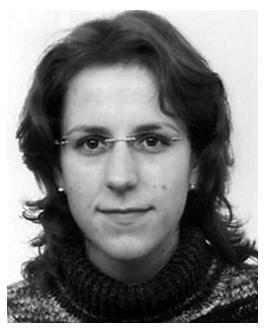

Linda Salavcová received the MSc. degree in chemistry and technology of inorganic materials from the Institute of Chemical Technology, Prague, Czech Republic, in 2003, where she is currently working toward the Ph.D. degree in the Faculty of Chemical Technology.

Her current work includes material analysis and fabrication of optical waveguides by ion exchange.

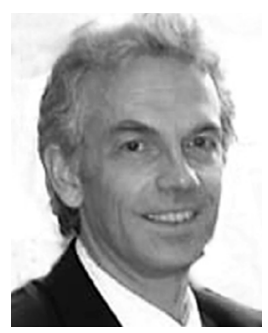

Martin Míka received the M.S. degree in technology of silicates and the Ph.D. degree in chemistry and technology of inorganic materials from the Institute of Chemical Technology, Prague, Czech Republic, in 1988 and 1995, respectively.

Since 1995, he has been with the Institute of Chemical Technology, presently as an Associate Professor. His current interests include all aspects of glass and amorphous materials science and technology.

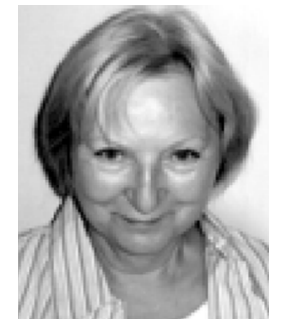

Jarmila Špirková graduated from the Faculty of Natural Sciences at the Charles University, Prague, Czech Republic, and from the Institute of Chemical Technology, Prague, Czech Republic.

Since 1972, she has been staff member of the Institute of Chemical Technology as an Assistant Professor. Her scientific and pedagogical activity deals with materials chemistry research, mainly for passive and active waveguides in lithium niobate and optical glasses.

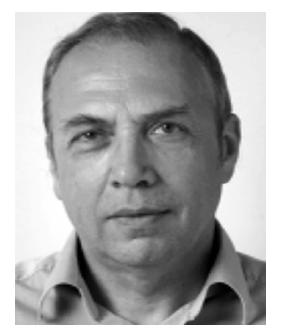

Jiří Čtyroký (M'90-SM'99) received the M.Sc. and $\mathrm{Ph} . \mathrm{D}$. degrees in electronics and applied physics from the Czech Technical University, Prague, Czech Republic, in 1968 and 1972, respectively.

Since 1973 he has been Research Scientist with the Institute of Radio Engineering and Electronics (presently Institute of Photonics ane Electronics) ASCR. He is also Professor of applied physics at the Czech Technical University, Prague. His interests have been focused mainly to theory and modeling of integrated photonic devices.

Dr. Čtyroký is Fellow of the Institute of Physics and member of OSA and the Czech and Slovak Society for Photonics. 